\title{
Rare case of pneumorrhachis, pneumomediastinum, pneumothorax, and surgical emphysema secondary to bronchial asthma
}

This article was published in the following Dove Press journal:

International Medical Case Reports Journal

6 March 2014

Number of times this article has been viewed

\author{
Parag Suresh Mahajan' \\ Nasser Jassim Al \\ Maslamani' \\ Nishan K Purayil ${ }^{2}$ \\ 'Department of Radiology, ${ }^{2}$ Accident \\ and Emergency Department, Al Khor \\ Hospital, Hamad Medical Corporation, \\ Doha, Qatar
}

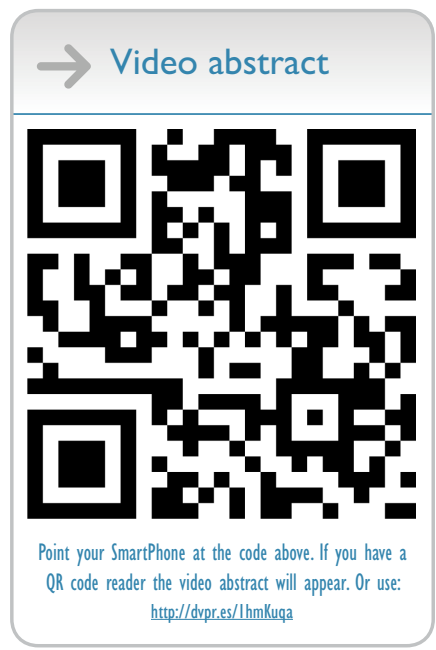

Correspondence: Parag Suresh Mahajan Department of Radiology, Al Khor Hospital, Hamad Medical Corporation, PO Box 3050, Doha, Qatar

Tel +97466347694

Email mdfrcr@gmail.com

\begin{abstract}
Air localized within the spinal canal is called pneumorrhachis. In the case of pneumorrhachis, air can be present in the extradural, the intradural, or the subarachnoid space of the spinal canal. The air within the soft tissue of the posterior mediastinum may dissect along fascial planes, through the intervertebral neural foramina, and into the extradural or the subarachnoid space. Nontraumatic pneumorrhachis is a rare presentation. Most of the time, pneumorrhachis is asymptomatic, remains localized, and resolves spontaneously. There are very few reports of combined presence of pneumomediastinum and extradural pneumorrhachis not associated with thoracic injury in the published literature. We report a rare case of pneumorrhachis, pneumomediastinum, pneumothorax, and surgical emphysema in an adult female patient developed after a bout of violent cough related to bronchial asthma.
\end{abstract}

Keywords: pneumorrhachis, pneumomediastinum, pneumothorax, surgical emphysema, asthma

\section{Introduction}

Pneumorrhachis is defined as air localized within the spinal canal: in the extradural space; in the intradural space; or in the subarachnoid space. It is a rare condition and is usually incidentally detected during radiological investigations. ${ }^{1}$ In the radiology practice, it is often associated with severe spinal trauma or is iatrogenic. Most of the time, pneumorrhachis is asymptomatic and is not clinically significant. Pneumorrhachis tends to remain localized and resolves spontaneously. ${ }^{1}$

Common causes of pneumorrhachis include: penetrating trauma; an invasive procedure like an epidural analgesia or a lumbar puncture; spontaneous or traumatic pneumomediastinum and pneumothorax; degenerative disc disease; or extradural abscess. Bronchial asthma that causes pneumorrhachis is a very rare condition. ${ }^{1-6}$ To our knowledge, very few cases of this association are reported in the published literature. ${ }^{1-6}$ Pneumorrhachis secondary to interstitial lung disease was reported by Sandhya et al in $2011 .^{7}$ A case of pneumorrhachis related to the common flu was recently reported. ${ }^{8}$ Pneumorrhachis secondary to peanut aspiration was also reported. ${ }^{9}$ We present a rare case of pneumorrhachis, pneumomediastinum, pneumothorax, and surgical emphysema secondary to an acute attack of bronchial asthma.

\section{Case report}

An 18-year-old female Arab, a known asthmatic, presented to the emergency department of our hospital with complaints of chest pain and a nonproductive cough of 1-hour duration. She was conscious and well-oriented to the surroundings but had mild dyspnea. 
There was no history of receiving assisted mechanical ventilation. There was no previous history of pulmonary tuberculosis, recent trauma, surgery, or other intervention.

Vital parameters were stable, and body temperature was normal. There was subcutaneous emphysema involving the right side of the neck. Auscultation of the chest did not reveal any significant abnormality. A chest radiograph was obtained, which revealed surgical emphysema along the upper part of the right lateral chest wall and the right side of the neck. Minimal pneumomediastinum was also noted with air within the superior mediastinum on the right. A loss of volume of the right lung was noted with a shift of mediastinum to the right and elevated right diaphragmatic dome (Figure 1). No lung consolidation, pneumothorax, or pleural collection was noted. The patient collapsed immediately after the chest radiograph was obtained. She was intubated and given intravenous fluids and vasopressors to control the hypotension. Her condition stabilized after 2 hours. The portable bedside chest radiograph revealed increased severity of pneumomediastinum, surgical emphysema, right lung collapse, and mediastinal shift to the right (Figure 2).

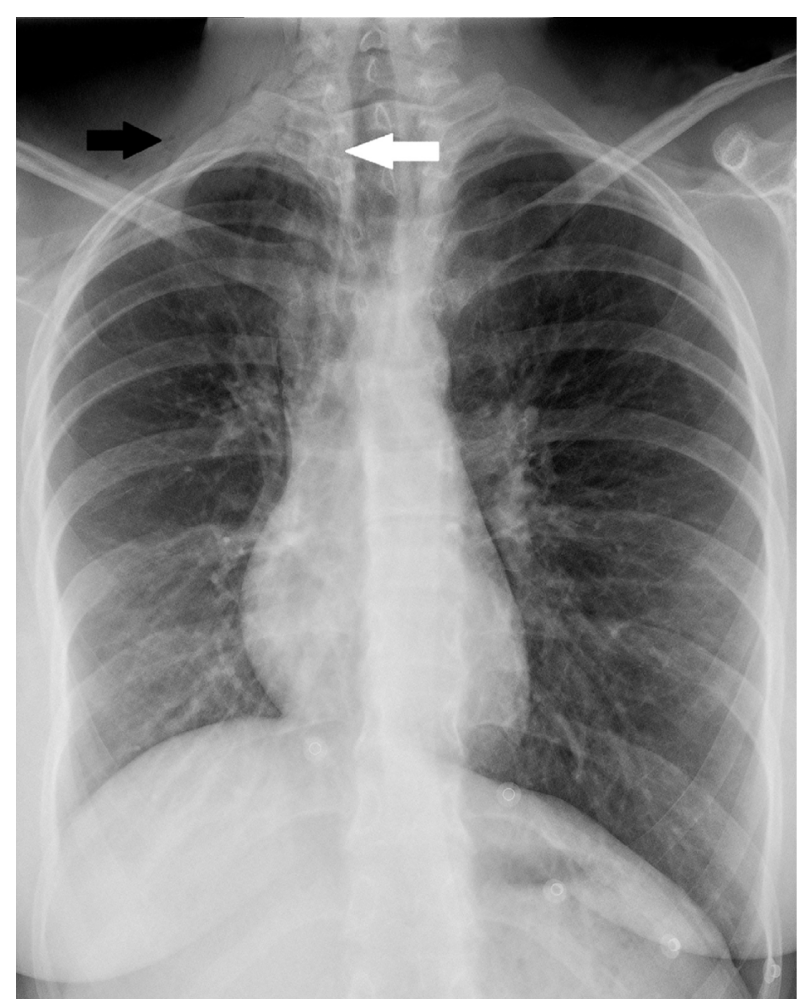

Figure I Frontal chest radiograph.

Notes: This frontal chest radiograph demonstrates surgical emphysema along the upper part of the right lateral chest wall and the right side of the neck (black arrow), air within the superior mediastinum on the right (white arrow), and the loss of volume of the right lung leading to a mediastinal shift to the right and the elevation of the right diaphragmatic dome.

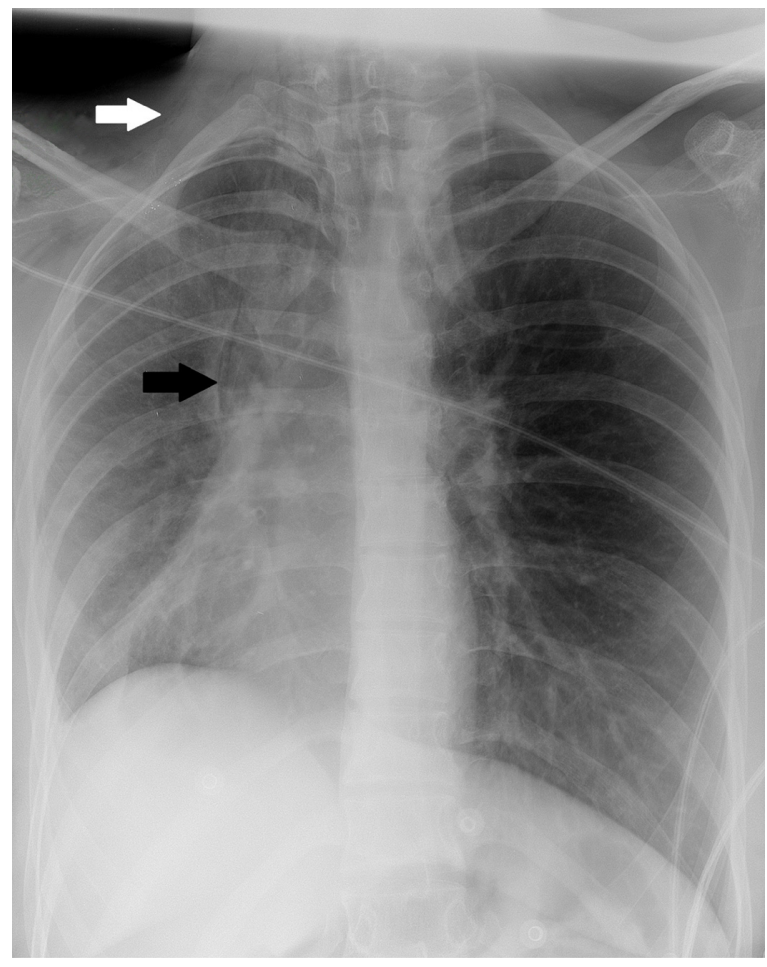

Figure 2 Portable bedside semi-sitting chest radiograph.

Notes: This radiograph shows the increased severity of pneumomediastinum (white arrow), surgical emphysema (black arrow), right lung collapse, and mediastinal shift to the right.

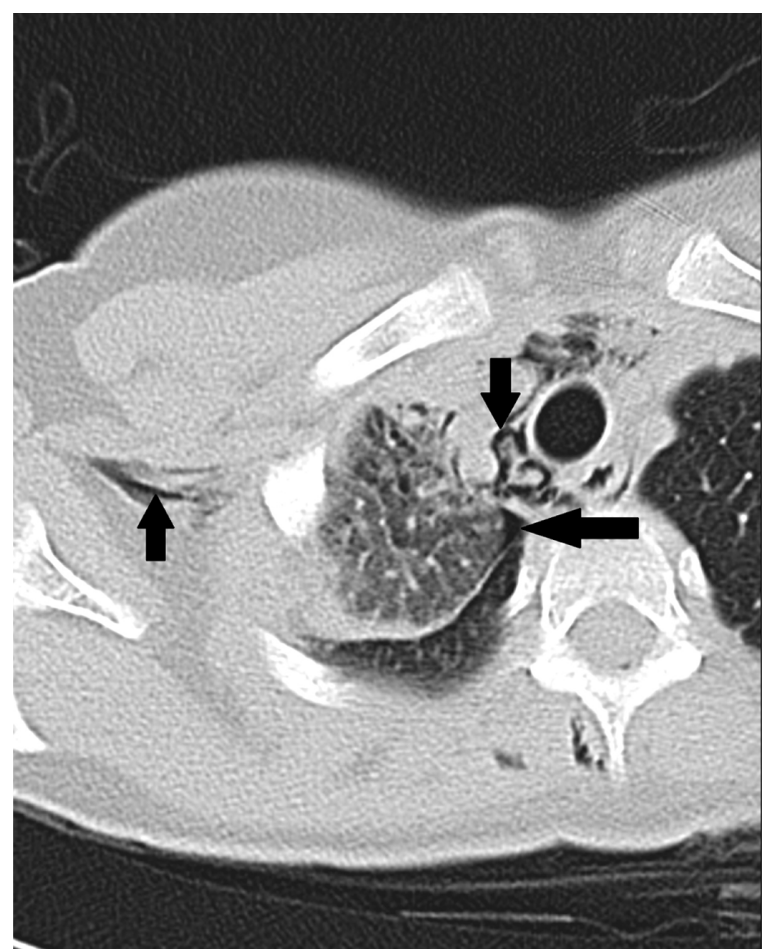

Figure 3 Axial nonenhanced chest CT scan.

Notes: This chest scan shows air dissecting through the mediastinal spaces (down arrow) and the subcutaneous soft tissue (up arrow). Minimal pneumothorax is also noted (left directional arrow).

Abbreviation: CT, computed tomography. 


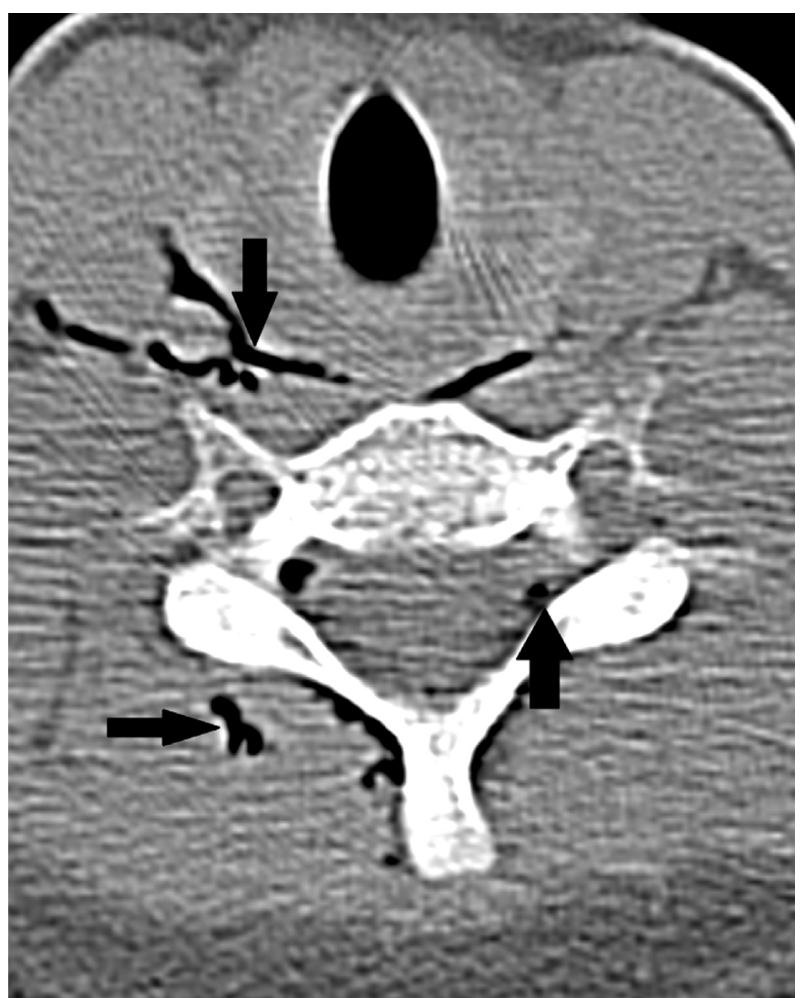

Figure 4 Axial nonenhanced chest CT scan.

Notes: This chest CT scan shows air dissecting through the mediastinal spaces (down arrow) and the subcutaneous soft tissue (right directional arrow). Air is also noted within the extradural space in the lower cervical and the upper thoracic spine (up arrow).

Abbreviation: CT, computed tomography.

Computed tomography (CT) imaging of the thorax was also performed, which confirmed the dissection of air into the mediastinal and subcutaneous spaces (Figure 3). A CT scan also revealed air within the posterior spinal extradural space in the thoracic spine (Figures 4 and 5), minimal pneumothorax on the right, and obstruction of the segmental right upper lobe bronchus by mucus plugs (Figure 6).

She was hospitalized and treated with antibiotics, bronchodilators, oxygen inhalation, and other conservative measures. A bronchoscopic removal of mucus plugs and thick secretions was also performed. After only 5 days, clinical findings got better. The chest radiograph revealed resolution of the pneumomediastinum and surgical emphysema and a significant improvement of the right lung collapse and mediastinal shift to the right (Figure 7). She improved rapidly during her stay in the hospital and was discharged after 7 days.

\section{Discussion}

Pneumorrhachis can be classified by etiology into traumatic, nontraumatic, and iatrogenic types. ${ }^{1}$ Pneumorrhachis usually does not cause any symptoms and is, most of the time, incidentally detected. Pneumorrhachis that is not associated with trauma or intervention is a very rare condition. Pneumorrhachis has been described secondary to spontaneous or nontraumatic pneumomediastinum or pneumothorax. ${ }^{10}$ There are very few reports of the combined presence of pneumomediastinum and extradural pneumorrhachis that are not associated with thoracic injury in the published literature.

Our patient developed pneumorrhachis, pneumomediastinum, pneumothorax, and surgical emphysema without any trauma. Air within the spinal canal is usually an isolated finding. It may be detected in the cervical, thoracic, or lumbosacral regions - or the entire spinal canal. Pneumorrhachis commonly remains localized. ${ }^{1}$ In our case, pneumorrhachis was extradural and localized in the lower cervical and upper thoracic spine.

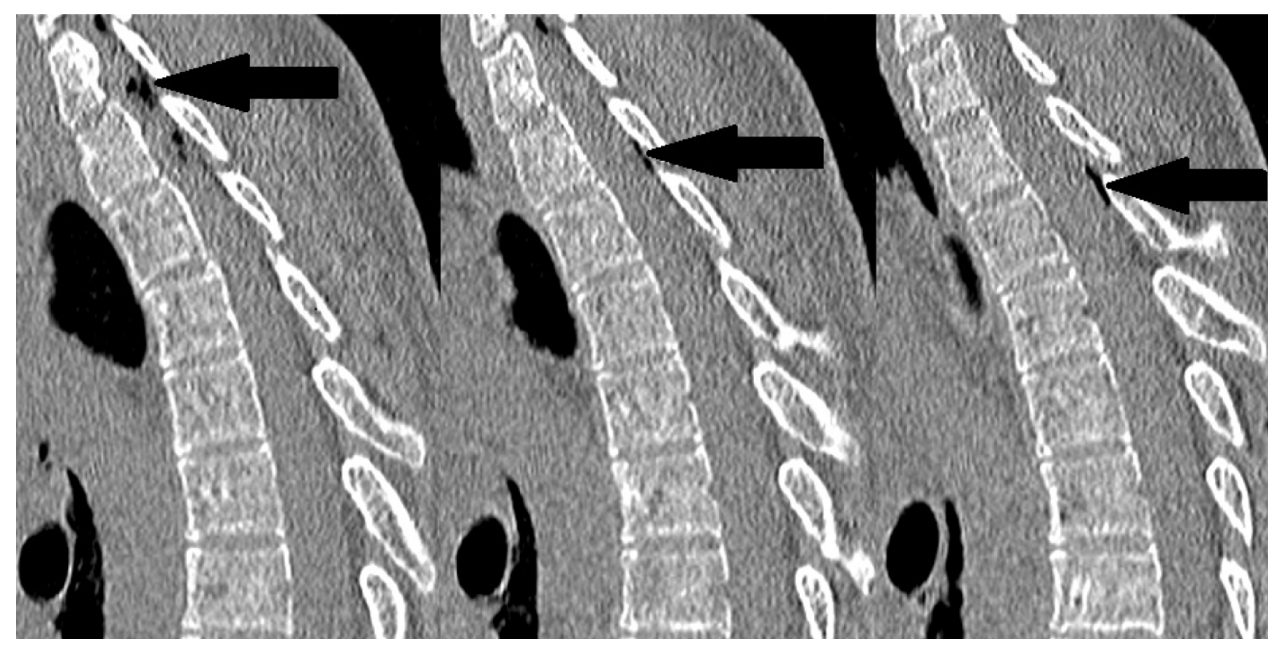

Figure 5 Sagittal reformatted CT scan images of chest.

Notes: This chest scan demonstrates air within the extradural space in the lower cervical and upper thoracic spine (arrows).

Abbreviation: CT, computed tomography. 


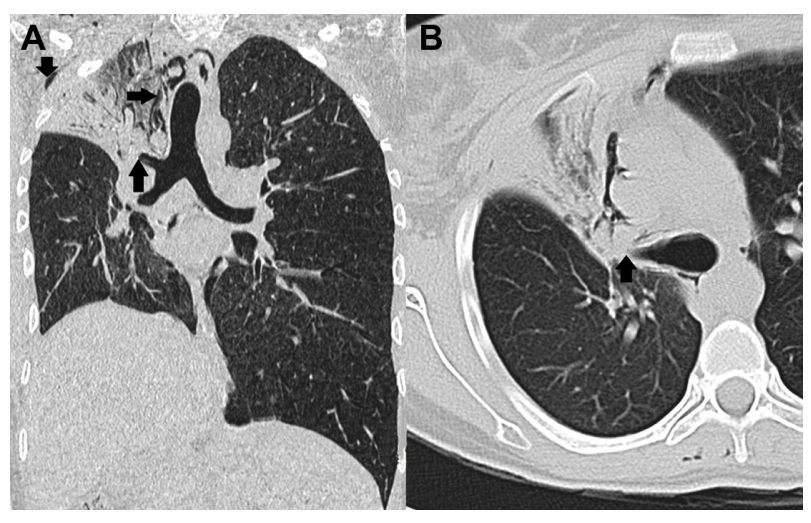

Figure 6 Coronal and axial reformatted CT scan images of the chest.

Notes: (A) This CT scan image demonstrates surgical emphysema along the upper part of the right lateral chest wall and the right side of neck (down arrow), air within the superior mediastinum on right (right directional arrow), loss of volume of the right lung leading to the mediastinal shift to the right, elevation of the right diaphragmatic dome, and obstruction of the segmental right upper lobe bronchus by mucus plugs (A and B) (up arrows).

Abbreviation: CT, computed tomography.

Pneumorrhachis is primarily a clinical imaging diagnosis, and clinicians do not play any role in its diagnosis, as pneumorrhachis is almost always asymptomatic. Pneumorrhachis can be diagnosed on a radiograph or a CT scan of the spine. A CT scan is the investigation of choice in its diagnosis. ${ }^{1,8-11}$

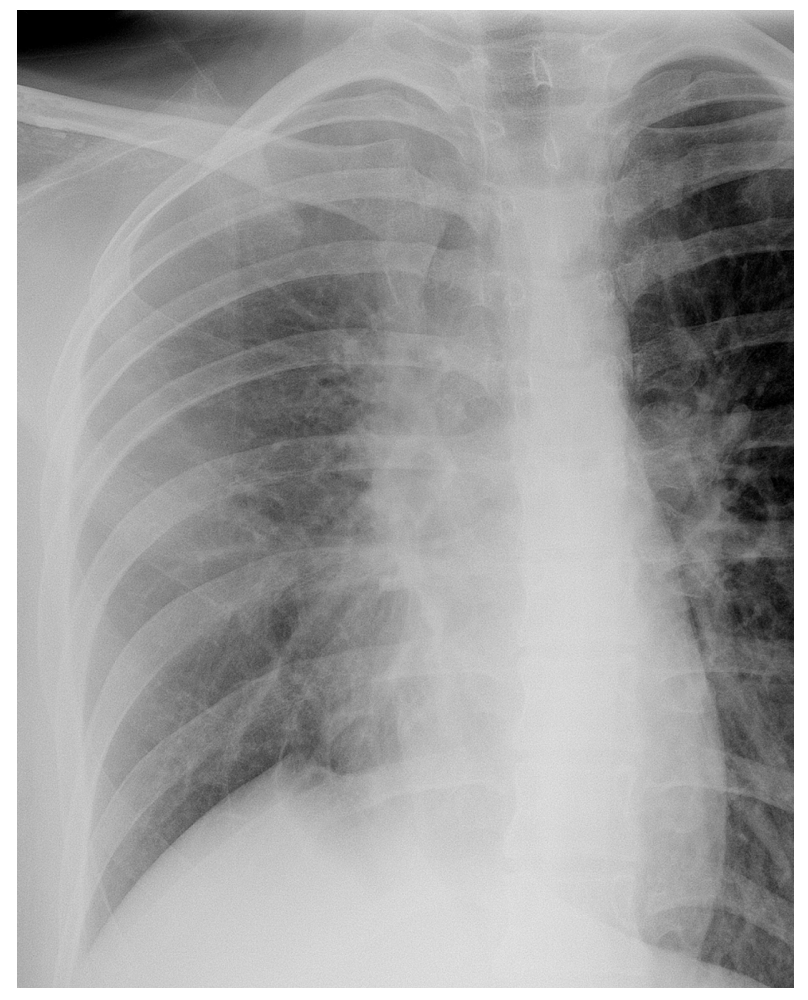

Figure 7 Follow-up frontal chest radiograph.

Notes: This chest radiograph demonstrates the complete resolution of surgical emphysema and pneumomediastinum and significant inflation of the right lung on the fifth hospital admission day.
In our case, also, the pneumorrhachis was asymptomatic and incidentally detected on a chest CT scan. A violent cough can sometimes occur in bronchial asthma, may cause sudden elevation of intra-alveolar pressure, and consequently may lead to a rupture of the peripheral pulmonary alveoli. ${ }^{1}$

The leaked air dissects through the perivascular interstitium of the lung and may traverse through the fascial planes from the retropharyngeal space or the mediastinum. Air traversing through the fascial planes may pass through the intervertebral neural foramina into the spinal canal. ${ }^{1}$ There are no barriers along the fascia to prevent this spread of air from the chest to the spinal canal. ${ }^{1}$

The patient collapsed immediately after obtaining the first radiograph likely due to an acute lung collapse, which - in turn - may have been caused by an obstruction by a mucus plug or a blood clot. Increased right lung collapse was detected on the subsequent chest radiograph. The severe collapse of a lung as a result of large mucus plugs occluding major airways has been described in many studies on different lung diseases, including bronchial asthma. ${ }^{12}$ Occluding large mucus plugs may cause reduced gas exchange, increasing inspiratory pressure, and breathing difficulty. ${ }^{12}$

In most cases, extradural pneumorrhachis is self-limiting and resolves spontaneously when the etiological entity is taken care of. In our case also, the pneumorrhachis resolved spontaneously. A rare case of symptomatic pneumorrhachis having neurological deficits has been reported. ${ }^{11}$

\section{Conclusion}

In conclusion, we present a very rare case of extradural pneumorrhachis due to pneumomediastinum, which - in turn - was secondary to bronchial asthma. Most cases of pneumorrhachis can be managed conservatively, as spontaneous resolution is common. Pneumorrhachis is, thus, a benign condition. However, it is essential for the treating physician to study carefully the associated disease conditions and neurological status of the patient, as neurological deficits may occur in some cases. ${ }^{11}$

\section{Disclosure}

The authors report no conflicts of interest in this work.

\section{References}

1. Karaoglan A, Cal MA, Orki A, Arpaozu BM, Colak A. Pneumorrhachis associated with bronchial asthma, subcutaneous emphysema and pneumomediastinum. Turk Neurosurg. 2011;21(4):666-668.

2. Pérez Frutos MD, Cerezo Arias MO, Córdoba López A, Granado Martínez D. [Pneumorrhachis: a rare complication of an asthma episode]. Med Intensiva. 2011;35(2):130-131. Spanish. 
3. Manden PK, Siddiqui AH. Pneumorrhachis, pneumomediastinum, pneumopericardium and subcutaneous emphysema as complications of bronchial asthma. Ann Thorac Med. 2009;4(3):143-145.

4. Eesa M, Kandpal H, Sharma R, Misra A. Spontaneous pneumorrhachis in bronchial asthma. Acta Radiol. 2006;47(7):672-674.

5. Oertel MF, Korinth MC, Reinges MH, Gilsbach JM. Pneumorrhachis of the entire spinal canal. J Neurol Neurosurg Psychiatry. 2005;76(7):1036.

6. van der Klooster JM, Grootendorst AF, Ophof PJ, Brouwers JW. Pneumomediastinum: an unusual complication of bronchial asthma in a young man. Neth J Med. 1998;52(4):150-154.

7. Sandhya P, Keshava SN, Danda D, Padhan P, Mathew J, Gibikote S. Pneumorrhachis and pneumomediastinum in connective tissue diseaserelated interstitial lung disease: case series from a tertiary care teaching hospital in South India. Rheumatol Int. 2012;32(5):1415-1419.
8. Patel V, Raval G, Gavadia K. Pneumothorax, pneumomediastinum, subcutaneous emphysema and pneumorrhachis as complications of common flu. Am J Case Rep. 2012;13:198-201.

9. Sankar J, Jain A, Suresh CP. Peanut aspiration leading to pneumorrhachis in a pre-schooler. BMJ Case Rep. 2013;2013.

10. Migeot M, Kessler R, Etxeberria Izal A, Rutgers MP, Gille M. Pneumorrhachis associated with a spontaneous pneumomediastinum. Rev Neurol (Paris). 2013;169(2):173-174.

11. Kim SW, Seo HJ. Symptomatic epidural pneumorrhachis : a rare entity. J Korean Neurosurg Soc. 2013;54(1):65-67.

12. Gurjar M, Singhal S, Poddar B, Singh RK. Collapse of left lung after endotracheal intubation: Is it always due to misplacement of tube? J Emerg Trauma Shock. 2010;3(3):305.

\section{Publish your work in this journal}

The International Medical Case Reports Journal is an international, peer-reviewed open-access journal publishing original case reports from all medical specialties. Previously unpublished medical posters are also accepted relating to any area of clinical or preclinical science. Submissions should not normally exceed 2,000 words or
4 published pages including figures, diagrams and references. The manuscript management system is completely online and includes a very quick and fair peer-review system, which is all easy to use. Visit http://www.dovepress.com/testimonials.php to read real quotes from published authors.

Submit your manuscript here: http://www.dovepress.com/international-medical-case-reports-journal-journal 